\title{
Association of Tobacco Products Use and Diabetes Mellitus-Results of a National Survey Among Adults in Saudi Arabia
}

Abdalla Abdelwahid Saeed

Faculty of Medicine, KSAU-HS, King Fahad Medical City, Community Medicine, Riyadh, Saudi Arabia

\begin{abstract}
Objective: To compare the tobacco products use patterns of known diabetics and non diabetics.

Material and Methods: A community-based cross-sectional study using STEPwise approach among adults using a multistage, stratified, cluster random sample. Data was collected using a questionnaire which included sociodemographics; tobacco products use habits, history of diabetes, biochemical and anthropometric measurements.

Results: Of the total of 4654 subjects who participated in the study, 1016 (21.8\%) were ever smoked tobacco products users and 65 (1.4\%) were ever smokeless tobacco products users. Known Diabetes prevalence was $15.3 \%$ (712 known diabetics). There were no significant differences in diabetic status and smokeless tobacco products use for both ever and current use. For smoked products diabetics are fewer in current smokers and more in ex smokers.
\end{abstract} Diabetics started smoking significantly older, smoked for longer duration and higher intensity than non diabetics.

Conclusion: Diabetes appears to be associated with smoked but not smokeless tobacco products use.

Key Words: Tobacco use, diabetes, adults, Saudi Arabia

Received: 27.12.2011 Accepted: 08.05.2012

\section{Introduction}

Diabetes mellitus (DM) is a multifactorial disease where both genetic and environmental factors have significant roles. It is one of the primary causes of disability and premature death in both the developed and developing world (1). The burden of type 2 diabetes is high in the Kingdom of Saudi Arabia (KSA) in terms of morbidity and mortality (2-5). On the other hand, the harmful consequences of smoking on health are well documented $(6,7)$. It is estimated that governments would save money and avoid many premature deaths if smoking is prevented (8). The tragedy is that smoking is on the rise in most developing countries, including Saudi Arabia (9).

Some older studies reported that the relationship between past smoking and the risk of DM is still unclear (10-12). However, smoking as a risk factor for type 2 diabetes mellitus was reported from many recent international studies (13-20). These cohort and cross-sectional studies suggest that smoking may be an independent and modifiable risk factor for the development of type 2 diabetes. They showed that smokers had a higher diabetes mellitus incidence rate than non smokers and quitting smoking reduced the incidence of diabetes. Smoking increases insulin resistance, worsens diabetes control and all-cause mortality is higher in those who smoke than in those who do not (21). The association of smoking and diabetes was not studied in KSA previously and previous studies on diabetes in KSA did not discuss smoking as a predictor or risk factor of DM (2-5). This study aims to outline the association of tobacco products use and type 2 diabetes mellitus among adults. It is hoped that the results may be of help in designing programs to prevent and control the disease.

\section{Material and Methods}

This was a cross-sectional, community based study covering the whole of the Kingdom of Saudi Arabia in 2005 the WHO STEPwise approach to Surveillance (STEPS) of NonCommunicable Diseases (NCD) risk factors was the basis for conducting the survey and collecting data $(22,23)$.

\section{Study population}

The study population was the total Saudi population aged 15-64 years of all the 20 health regions of the country.

\section{Sampling}

A multistage stratified cluster random sampling technique was used to recruit the study subjects. Stratification was based on age (Five 10 year age groups), gender (2 groups) and health regions of country. Based upon the proposed methodology of the WHO STEPwise approach, a sample size of 196 was calculated for each of these ten strata. A list of all Primary Health Care Centers (PHCCs) in 
each region was prepared and $10 \%$ of these PHCCs were randomly chosen, and a regional sample allocated to them proportionate to the size of their catchment population in sampled PHCCs. To identify the households a map of the health center coverage area was used to choose the houses. Each house was assigned a number and a simple random draw was made.

\section{Data collection \\ Tool used}

Data was collected using the WHO STEPwise approach which includes a questionnaire, physical measurements plus biochemical measurements covering hypertension and other chronic diseases and risk factors. The questionnaire was translated into Arabic by a team of physicians and was back translated to ensure the accuracy of translation. The Arabic instrument was pre-tested on 51 eligible respondents for wording and understanding of the questions, and necessary adjustments were made in the instrument in light of the pre-test. The questionnaire includes sociodemographic data, history of blood pressure and blood pressure measurement in addition to other diseases and risk factors.

\section{Data collectors}

Data was collected by 54 male and 54 female collectors who worked in teams. Each field team was made up of four persons - a male data collector, a female data collector, a driver and a female assistant. Data collection teams were supervised by a hierarchy of local supervisor, regional coordinators and national coordinator.

\section{Training of data collectors}

All individuals involved in data collection attended comprehensive training workshops that included interview techniques, data collection tools, practical applications and field guidelines.

\section{Definition of Diabetes mellitus}

A subject is labeled diabetic if he/she a known diabetic as diagnosed by a health professional and under some form of management, pharmacological or non pharmacological, prescribed by a health professional.

\section{Definitions of tobacco use}

An ever daily smoker was defined as someone who had attempted smoking any tobacco product daily in the past Ever smokers can be currently non smokers (ex-smokers) or current smokers, daily or non daily. A never smoker was one who had never smoked.

\section{Data management}

Questionnaires collected from the field were reviewed by team leaders assigned to each team before submitting them to headquarters for data entry. Double entry of the questionnaires was performed using EPI-INFO 2000 software and EpiData software developed by the Menzes centre for validation. After data entry, data cleaning was conducted. New variables were defined by adopting the standard Steps variables (STEPS Data Management Manual, Draft version v1.5, October 2003).

\section{Statistical analysis}

The statistical analysis was performed using SPSS for Windows, version 17.0. The data were presented as mean \pm standard deviation for continuous variables and as counts and percentage for categorical variables. The Chi-square test was used for association between categorical variables and the t-test or Mann-Whitney U test and ANOVA or Kruskal Wallis tests were used as appropriate after checking for normality. Logistic regression was used to investigate the associations of the binary dependent variable "Diabetic status" with the independent tobacco use variables. The level of significance was set to be $<0.05$ throughout the study. The number of participants' responses used in the discrete statistical analyses varied due to missing data for certain variables.

\section{Ethical clearance and confidentiality}

The protocol and instrument of surveillance were approved by the Ministry of Health, Center of Biomedical Ethics and the concerned authorities in the Kingdom. Informed consent of all subjects was obtained. Confidentiality of data was assured and that data will be used only for the stated purpose of the survey.

\section{Results}

A total of 4654 subjects participated in the study. Table 1 shows age, gender, known diabetics distribution and ever smoking tobacco products use. Females (50.4\%) were slightly more than males, with the adolescent $15-24$ years of age (22.5\%) almost double the elderly $55-64$ years (11.5\%). Known diabetics totaled 712 , giving a prevalence of $15.3 \%$. Table 2 shows the diabetic status according to smoking habits of

Table 1. Distribution of known diabetics according to age and gender $\mathbf{n}$ (\%)

\begin{tabular}{|c|c|c|c|c|c|c|}
\hline $\begin{array}{l}\text { Age (years) } \\
\% \text { of total }\end{array}$ & $\begin{array}{l}15-24 \\
22.5 \%\end{array}$ & $\begin{array}{l}25-34 \\
23.7 \%\end{array}$ & $\begin{array}{l}35-44 \\
24.5 \%\end{array}$ & $\begin{array}{l}45-54 \\
17.8 \%\end{array}$ & $\begin{array}{l}55-64 \\
11.5 \%\end{array}$ & Total \\
\hline Gender & & & Known diabet & & & \\
\hline Males | 2312 (49.6) & $11(2.1)$ & $13(2.7)$ & $70(13.6$ & $132(31.1)$ & $143(40.1)$ & $369(16.0)$ \\
\hline Females 2345 (50.4) & $12(2.4)$ & $27(4.3)$ & $92(14.7)$ & $124(30.6)$ & 88 (48.9) & $343(14.6)$ \\
\hline Total & $23(3.2)$ & $40(5.6)$ & $162(22.8)$ & $256(40.0)$ & $231(32.4)$ & $712(100)$ \\
\hline
\end{tabular}


Table 2. Smoking habit of smoked tobacco products according to diabetes mellitus status

\begin{tabular}{|c|c|c|c|c|}
\hline \multirow[t]{3}{*}{ Smoking habit } & \multicolumn{2}{|c|}{ Diabetes status } & \multirow{3}{*}{$\begin{array}{c}\text { Total } \\
100(4654)\end{array}$} & \multirow[t]{3}{*}{$p$ value } \\
\hline & Diabetic \% (n) & Non diabetic \% (n) & & \\
\hline & $15.3(711)$ & 84.7 ( 3943$)$ & & \\
\hline \multicolumn{5}{|l|}{ Ever smoking status } \\
\hline Smoker & 21.7 (154) & $21.9(862)$ & $21.8(1016)$ & 0.474 \\
\hline Non smoker & $78.3(557)$ & $78.1(3081)$ & $78.2(3638)$ & \\
\hline \multicolumn{5}{|l|}{ Ever daily smoking status } \\
\hline Ever smoked in the past & $16.2(115)$ & $12.2(481)$ & $12.8(596)$ & 0.001 \\
\hline Never smoked in the past & $83.8(596)$ & $87.8(3462)$ & $87.2(4058)$ & \\
\hline \multicolumn{5}{|l|}{ Current smoking status } \\
\hline Currently smoking & $9.4(67)$ & $11.9(470)$ & $11.5(537)$ & 0.029 \\
\hline Currently not smoking & $90.6(644)$ & $88.1(3473)$ & $88.5(4417)$ & \\
\hline \multicolumn{5}{|c|}{ Current daily smoking status } \\
\hline Daily smoker & $8.6(61)$ & $11.7(461)$ & $11.2(522)$ & 0.015 \\
\hline Non daily smoker & $91.4(650)$ & $88.3(3482)$ & $88.8(4132)$ & \\
\hline
\end{tabular}

Table 3. Smoking habit of smokeless tobacco products according to diabetes mellitus status with odds ratio and $95 \%$ confidence interval

\begin{tabular}{|c|c|c|c|c|}
\hline \multirow{3}{*}{$\begin{array}{l}\text { Smoking habit } \\
\text { Smokeless tobacco products }\end{array}$} & \multicolumn{2}{|c|}{ Diabetes status } & \multirow{3}{*}{$\begin{array}{c}\text { Odds ratio } \\
\text { (95\% Confidence } \\
\text { Interval C.I) }\end{array}$} & \multirow[t]{3}{*}{$P$ value } \\
\hline & Diabetic \% (n) & Non diabetic \% (n) & & \\
\hline & $15.3(711)$ & $84.7(3943)$ & & \\
\hline Ever smoker & $1.3(9)$ & $1.4(56)$ & $0.890(0.458-1.907)$ & 0.747 \\
\hline Never smoker & 98.7 (702) & $98.6(3887)$ & & \\
\hline Current smoker & $33.3(3)$ & $66.1(37)$ & $0.257(0.058-1.142)$ & 0.076 \\
\hline Current non smoker & $66.7(6)$ & 33.9 (19) & & \\
\hline
\end{tabular}

Table 4. Age of initiation of smoking, duration and intensity of tobacco products use and diabetes status

\begin{tabular}{|lccc|}
\hline Variable/Diabetic status & \multicolumn{1}{c|}{ Meantstandard deviation } & p value \\
\cline { 2 - 3 } & Diabetic & Non diabetic & 0.016 \\
\hline Age of initiation of smoking (years) & $23.6 \pm 16.7$ & $20.3 \pm 12.8$ & 0.032 \\
Total duration of smoking (weeks) & $25.4 \pm 11.7$ & $15.8 \pm 11.3$ & 0.476 \\
Age stopped smoking (years) & $42.4 \pm 19.4$ & $35.4 \pm 19.7$ & 0.010 \\
Number of cigarettes per day & $22.6 \pm 14.6$ & $17.3 \pm 10.9$ & $<0.001$ \\
Number of shisha per day & $3.8 \pm 4.3$ & $2.8 \pm 1.7$ & 0 \\
\hline
\end{tabular}

smoked tobacco products. Ever smokers were 1016 (21.8\%). There was no significant association between the ever smoking habit and known diabetes. There is, however, a significant association with ever daily smoking habit. Known diabetics were significantly more ever daily smokers than non diabetics. The reverse is true for current smoking status, where known diabetics were significantly fewer current smokers than non diabetics. Only 64 (1.4\%) subjects ever used smokeless tobacco products. No significant association was found between diabetic status and ever and current smokeless tobacco as depicted in Table 3. Table 4 compares age of initiation of smoking, age of cessation, duration and intensity of smoking among known diabetics and non diabetics. Diabetics started smoking significantly older, smoked for longer duration and at higher intensity than non diabetics. All significant variables in the bivariate analysis were entered in the logistic regression model for predictors of known diabetics, as shown in Table 5. Only the age of initiation of daily smoking was a significant predictor of diabetic status, with diabetics starting smoking at an older age. 
Table 5. Multiple logistic regression analysis for tobacco use predictors of diabetes mellitus

\begin{tabular}{|lccccccc|}
\hline Predictors & \multicolumn{1}{c}{} & & & & \multicolumn{2}{c|}{$95.0 \%$ C.I.O.R. ${ }^{* *}$} \\
& B & S.E. & Wald & Sig. & O.R.* & Lower & Upper \\
\hline Number of cigarettes per day & .002 & .060 & .001 & .973 & 1.002 & .891 & 1.127 \\
Ever daily smoking & .630 & .409 & 2.377 & .123 & 1.878 & .843 & 4.186 \\
Duration of smoking & -.077. & .063 & 1.490 & .222 & .926 & .819 & 1.048 \\
Initiation age of smoking & -.031. & .011 & 7.568 & .006 & .970 & .949 & .991 \\
Constant & 2.691 & .756 & 12.660 & .000 & 14.751 & & \\
\hline O.R. ${ }^{*}=$ Odds Ratio, 95.0\% C.I.O.R. ${ }^{* *}=95 \%$ Confidence Interval for Odds Ratio & & & & \\
\hline
\end{tabular}

\section{Discussion}

The magnitude of tobacco products use as a public health challenge is growing in terms of morbidity andmortality, with large demands on health care systems and increasing cost (24-26). The prevalence of ever smoked tobacco products was nearly $22 \%$ among adults in this study, confirming the seriousness of the problem. Smokeless tobacco prevalence is minimal and this is not unexpected as the habit is mostly localized in limited geographical locations, particularly the southern area (23). The prevalence of diabetes in this study is lower than other surveys and this also is not unexpected as our study population consists of only known diabetics under some form of treatment. Newly discovered diabetics during the survey were not included. No significant association was found between diabetes and smokeless tobacco products use in this study. Some studies reported similar findings, while others found that current or lifetime smoking or use of smokeless tobacco is very likely to cause the disease $(27,28)$. The apparent inconsistency of the results may be due, in addition, to possible confounders, to differences in methods, sampling, assessment of smoking status and biased recall. Diabetics are significantly more ever smoked tobacco products users than non diabetics but significantly fewer current smokers that non diabetics. This could be due to smoking cessation advice among diabetics. This study found that longer durations and higher intensity of smoked tobacco products use were significant risk factors for diabetes among adults in the KSA. This is in agreement with a number of studies which reported that smoking could be independently associated with glucose intolerance, impaired fasting glucose, and development of type 2 diabetes (13-20, 29-32). These studies showed a dose-response relationship between smoking and incidence of diabetes, that cigarette smoking is an independent and modifiable determinant of type 2 diabetes mellitus and that smokers who quit may derive substantial benefit from doing so (33). Health and research authorities in some countries included smoking as a variable in a score of variables predicting diabetes (34).

In general, this study showed that daily smoked tobacco products use appears to be a significant risk factor for diabetes among adults. There is theoretical, biological plausibility that smoking may lead to insulin resistance or inadequate compensatory insulin secretion, impaired glucose tolerance, with a direct effect on beta cells and chronic pancreatitis (31, $32,35,36)$. Other possible explanations for this association can be due to unhealthy habits such as lack of physical activity, poor fruit and vegetable intake (37-39).

There are some inconsistencies in the results of this study. These include lack of association of smokeless tobacco use and diabetes and starting smoking at an older age, which is a significant predictor of diabetes among known diabetics. There is a need for studies that include detailed measurement and adjustment for potential confounding factors such as socioeconomic status, education, and exercise, with a goal of establishing whether there is a real association between diabetes and smoking tobacco use and whether the association is causal.

Whether tobacco products use is associated with smoking or not, it needs to be controlled due to its many other proven health risks. This calls for intervention strategies aiming at the prevention of acquiring the habit of smoking, reversing it if acquired, or reducing intensity by cessation programs. This effort is multisectorial involving, in addition to health authorities, education, youth and media authorities. In the meantime, all physicians and other health professionals should enquire about smoking habits in all clients generally and in diabetic patients particularly in order to offer quitting services for smokers.

\section{Study limitations}

The study sample consistd of only known diabetics and hence unknown diabetics may not show the same association with tobacco products. Smoking habits were self reported by subjects themselves and were not biochemically verified.

\section{Conclusion}

Diabetes appears to be significantly associated with daily smoked tobacco products but not with smokeless tobacco products use. Further studies are needed to confirm and quantify this association, taking in consideration possible confounders. Studies concentrating on smokeless tobacco products use and diabetes may be needed particularly in areas where the habit is prevalent.

\section{Conflict of Interest}

No conflict of interest was declared by the authors. 


\section{References}

1. Shaw JE, Sicree RA, Zimmet PZ. Global estimates of the prevalence of diabetes for 2010 and 2030. Diabetes Res Clin Pract 2010;87:4-14. [CrossRef]

2. Al-Daghri NM, Al-Attas OS, Alokail MS, Alkharfy KM, Yousef M, Sabico SL, et al. Diabetes mellitus type 2 and other chronic non-communicable diseases in the central region, Saudi Arabia (Riyadh cohort 2): a decade of an epidemic. BMC Med 2011;9:76. [CrossRef]

3. Al-Nozha MM, Al-Maatouq MA, Al-Mazrou YY, Al-Harthi SS, Arafah MR, Khali MZ, et al. Diabetes mellitus in Saudi Arabia. Saudi Med J 2004;25:1603-10.

4. Alqurashi KA, Aljabri KS, Bokhari SA. Prevalence of diabetes mellitus in a Saudi community. Ann Saudi Med 2011;31:19-23. [CrossRef]

5. Elhadd TA, Al-Amoudi AA, Alzahrani AS.Epidemiology, clinical and complications profile of diabetes in Saudi Arabia: a review. Ann Saudi Med. 2007;27:241-50. [CrossRef]

6. Wipfli $\mathrm{H}$, Samet JM. Global economic and health benefits of tobacco control: part 1. Clin Pharmacol Ther 2009;86:263-71. [CrossRef]

7. Warner KE. The economics of tobacco: myths and realities. Tob Control 2000;9:78-89. [CrossRef]

8. Joossens L, Merriman D, Ross H, Raw M. The impact of eliminating the global illicit cigarette trade on health and revenue. Addiction 2010;105:1640-9. [CrossRef]

9. Bassiony M. Smoking in Saudi Arabia. Saudi M J 2009;30:876-81.

10. Jarrett RJ, Shipley MJ. Type 2 (non-insulin-dependent) diabetes mellitus and cardiovascular disease--putative association via common antecedents; further evidence from the Whitehall Study. Diabetologia 1988;31:737-40. [CrossRef]

11. Perry IJ, Wannamethee SG, Walker MK, Thomson AG, Whincup $\mathrm{PH}$, Shaper AG. Prospective study of risk factors for development of non-insulin dependent diabetes in middle aged British men. BMJ 1995;310:560-4. [CrossRef]

12. Haire-Joshu D, Glasgow RE, Tibbs TL. Smoking and diabetes. Diabetes Care 1999;22:1887-98. [CrossRef]

13. Kowall B, Rathmann W, Strassburger K, Heier M, Holle R, Thorand B, et al. Association of passive and active smoking with incident type 2 diabetes mellitus in the elderly population: the KORA S4/F4 cohort study. Eur J Epidemiol 2010;25:393-402. [CrossRef]

14. Kowall B, Rathmann W, Strassburger K, Heier M, Holle R, Thorand $B$, et al. A prospective study investigating the association between environmental tobacco smoke exposure and the incidence of type 2 diabetes in never smokers. Ann Epidemiol 2011;21:42-7. [CrossRef]

15. Zhang L, Curhan GC, Hu FB, Rimm EB, Forman JP. Association between passive and active smoking and incident type 2 diabetes in women. Diabetes Care 2011;34:892-7. [CrossRef]

16. Xie $X T$, Liu $\mathrm{Q}, \mathrm{Wu} J$, Wakui M. Impact of cigarette smoking in type 2 diabetes development. Acta Pharmacol Sin 2009;30:784-7. [CrossRef]

17. Cho NH, Chan JC, Jang HC, Lim S, Kim HL, Choi SH. Cigarette smoking is an independent risk factor for type 2 diabetes: a fouryear community-based prospective study. Clin Endocrinol (Oxf) 2009;71:679-85. [CrossRef]

18. Hur NW, Kim HC, Nam CM, Jee SH, Lee HC, Suh I. Smoking cessation and risk of type 2 diabetes mellitus: Korea Medical Insurance Corporation Study. Eur J Cardiovasc Prev Rehabil 2007; 14:244-9. [CrossRef]

19. Tonstad S.Cigarette smoking, smoking cessation, and diabetes. Diabetes Res Clin Pract 2009;85:4-13. [CrossRef]

20. Yeh HC, Duncan BB, Schmidt MI, Wang NY, Brancati FL. Smoking, smoking cessation, and risk for type 2 diabetes mellitus: a cohort study. Ann Intern Med 2010;152:10-7.

21. Foy CG, Bell RA, Farmer DF, Goff DC Jr, Wagenknecht LE. Smoking and incidence of diabetes among U.S. adults: findings from the Insulin Resistance Atherosclerosis Study. Diabetes Care 2005;28:2501-7. [CrossRef]

22. Bonita R, de Courten $M$, Dwyer $T$, Jamorzik K, Winkelmann R. Surveillance of Risk factors for Non Communicable diseases. The WHO STEPwise approach. Geneva: World Health Organization; 2001. Summary $(\mathrm{WHO} / \mathrm{NMH} / \mathrm{CCS} / 01.01)$.

23. www.emro.who.int/ncd/pdf/stepwise_saa_05.pdf

24. Wagner EH, Groves T. Care for chronic diseases. BMJ 2002;325:9134. [CrossRef]

25. Hu F. Globalization of Diabetes The role of diet, lifestyle, and genes Diabetes Care 2011;34:1249-57. [CrossRef]

26. Mokdad AH, Ford ES, Bowman BA, Nelson DE, Engelgau MM, Vinicor $F$, et al. The continuing increase of diabetes in the US. Diabetes Care 2001;24:412. [CrossRef]

27. Eliasson M, Asplund K, Nasic S, Rodu B. Influence of smoking and snus on the prevalence and incidence of type 2 diabetes amongst men: the northern Sweden MONICA study. J Intern Med 2004;256:101-10. [CrossRef]

28. Persson PG, Carlsson S, Svanström L, Ostenson CG, Efendic S, Grill V. Cigarette smoking, oral moist snuff use and glucose intolerance. J Intern Med. 2000;248:103-10. [CrossRef]

29. Willi C, Bodenmann P, Ghali W, Faris P, Cornuz J. Active Smoking and the Risk of Type 2 Diabetes. A Systematic Review and Meta-analysis. JAMA 2007;298:2654-64. [CrossRef]

30. Chiolero A, Faeh D, Paccaud F, Cornuz J. Consequences of smoking on body weight, body fat distribution, and insulin resistance. Am J Clin Nutr 2008;87:801-9.

31. Haire-Joshu D, Glasgow RE, Tibbs TL. Smoking and diabetes. Diabetes Care 2004;1:S74-5.

32. Nakanishi N, Nakamura K, Matsuo Y, Suzuki K, Tatara K. Cigarette smoking and risk for impaired fasting glucose and type 2 diabetes in middle-aged Japanese men.Ann Intern Med 2000;133:183-91.

33. Voulgari C, Katsilambros N, Tentolouris N. Smoking cessation predicts amelioration of microalbuminuria in newly diagnosed type 2 diabetes mellitus: a 1-year prospective study. Metabolism 2011;60:1456-64. [CrossRef]

34. Hippisley-Cox J, Coupland C, Vinogradova Y, Robson J, Minhas R, Sheikh $A$, et al. Smoking was a variable in a score Predicting risk of type 2 diabetes in England and Wales: prospective derivation and validation of QDScore BMJ 2009;336:1475-82.

35. Carlsson S, Midthjell K, Grill V. Smoking is associated with an increased risk of type 2 diabetes but a decreased risk of autoimmune diabetes in adults: an 11-year follow-up of incidence of diabetes in the Nord-Trondelag study Diabetologia 2004;47:1953-6. [CrossRef]

36. Eliasson B. Cigarette smoking and diabetes. Prog Cardiovasc Dis 2003;45:405-13. [CrossRef]

37. van Dam RM, Rimm EB, Willett WC, Stampfer MJ, Hu FB. Dietary patterns and risk for type 2 diabetes mellitus in U.S. men. Ann Intern Med 2002;136:201-9.

38. Healton CG, Vallone D, McCausland KL, Xiao H, Green MP. Smoking, obesity, and their co-occurrence in the United States: cross sectional analysis. BMJ 2006;333:25-6. [CrossRef]

39. Thresia CU, Thankappan KR, Nichter M. Smoking cessation and diabetes control in Kerala, India: an urgent need for health education. Health Educ Res 2009;24:839-45. [CrossRef] 